and serves to streamline the review process by advising the investigator on minor corrections or clarifications that may otherwise delay approval ${ }^{3}$. For example, during pre-review, an investigator may be advised that his protocol lacks the required written assurance that the proposed activities do not unnecessarily duplicate

\title{
A word from OLAW and USDA
}

In response to the questions posed in this scenario, the Office of Laboratory Animal Welfare (OLAW) and the United States Department of Agriculture, Animal and Plant Health Inspection Service, Animal Care (USDA, APHIS, AC) offer the following clarification and guidance:

This column presents readers with a direct question: "are there any circumstances in which an IACUC Chairperson would be within his or her rights to reject apparently duplicative research before the protocol reached the full committee?" In addition, issues of ethical behavior, conflict of interest and noncompliance are raised by the scenario.

The Public Health Service (PHS) Policy on Humane Care and Use of Laboratory Animals (Policy) and the Animal Welfare Act and Regulations (AWARs) authorize a single direct responsibility to the IACUC Chairperson: to designate at least one member of the committee to conduct designated member review of protocols ${ }^{1,2}$. The APHIS Animal Care Inspection Guide recognizes the Chairperson as being responsible for all the activities of the IACUC, which include but are not limited to scheduling meetings, setting the meeting agenda, sending a list to members of protocols to be reviewed, moderating meetings, sending required reports to the Institutional Official and ensuring the facility's compliance with the AWARs ${ }^{3}$; the Chairperson may designate these responsibilities among the committee and IACUC staff. All other functions and responsibilities of the IACUC are for the full committee to consider and take appropriate action and are not for the Chairperson alone to decide.

The PHS Policy and the AWARs require that members not participate in the review or approval of protocols in which there is a conflicting interest ${ }^{1,2}$. In the scenario, the Chair determined to delay a proposal from IACUC consideration until he could prepare and have approved a similar protocol. This unethical action circumvented the committee's review for the Chairperson's personal advantage and is a conflict of interest that is unbefitting his appointment as Chairperson and IACUC member.

In the case of NIH-funded research, the PHS Policy and NIH Grants Policy Statement require verification of IACUC approval of those components related to the care and use of animals $s^{1,4}$. Federal requirements cannot be met if the protocol is not presented to the IACUC. Therefore, the Chairperson's actions constitute a reportable noncompliance to OLAW. In addition, the PHS Policy states that no PHS support for an activity involving animals will be provided unless the institution assumes responsibility for compliance with the Policy ${ }^{1}$. As such, compliance is an institutional responsibility. OLAW would expect the institutional leadership to take corrective measures to ensure the integrity and impartiality of the IACUC.

The AWARs are silent on how an institution can determine which research projects it will pursue. Those decisions are typically made at higher levels of the institution.

1. Public Health Service. Policy on Humane Care and Use of Laboratory Animals (US Department of Health and Human Services, Washington, DC, 1986; amended 2002).

2. Code of Federal Regulations. Title 9, Ch. 1, Part 2, Subpart C. §2.31(d)(2).

3. United States Department of Agriculture. Consolidated Inspection Guide (United States Department of Agriculture, Riverdale, MD, 2010). <http://www.aphis.usda.gov/animal_welfare/2011_ Inspection_Guide//9.8.3\%20Membership.pdf>

4. US National Institutes of Health. NIH Grants Policy Statement. Part II: Terms and Conditions of NIH Grant Awards. Subpart A. 4.1.1 Animal Welfare Requirements. (US National Institutes of Health, Bethesda, MD, 2012). <http://grants.nih.gov/grants/policy/nihgps_2012/nihgps_ch4.htm\#animal_ welfare_requirements>

Patricia Brown, VMD, MS, DACLAM

Director

OLAW, OER, OD, NIH, HHS
Chester Gipson, DVM

Deputy Administrator

USDA, APHIS, AC previous experiments ${ }^{1}$. Although it may be in the best interest of the investigator to address the comments, an investigator's refusal to make recommended changes cannot be used as grounds to deny formal review. The protocol must still move forward for FCR or DMR.

Alternatively, Finster may contend that he is withholding approval as a designated reviewer of the protocol. Although it is within his purview as IACUC Chair to assign himself this task, it is important to note that DMR may only be employed after all members have been provided the opportunity to call for FCR and that withholding of approval may only occur through $\mathrm{FCR}^{1,2}$. In this scenario, neither of these conditions has been met. Furthermore, there appears to be a conflict of interest (COI) on Finster's part. The AWARs (section 2.31(d)(2)) and the PHS Policy (section IV.C.2) state that members may not participate in IACUC review of a protocol for which they have a conflicting interest except to provide additional information as requested. Because Finster and Newsome engage in competing research, the potential for $\mathrm{COI}$ is high and Finster should recuse himself from review of her protocols. The IACUC would be well advised to develop a specific COI policy to address these situations.

An additional concern in this scenario is that Finster does not possess the qualities necessary to be an effective IACUC Chair. In large part, the Chair determines the culture of the IACUC. At a minimum, the Chair should be well versed in the regulatory requirements for conducting IACUC business and ideally, he or she should be collegial, transparent, diplomatic and ethical. Finster's behavior suggests that he has none of these qualities and is operating without the institution's best interests at heart. Perhaps it is time for a new IACUC Chair.

1. Animal Welfare Act Regulations. Code of Federal Regulations. Title 9, Chapter 1.

2. Public Health Service. Policy on Humane Care and Use of Laboratory Animals (US Department of Health and Human Services, Washington, DC, 1986; amended 2002).

3. Silverman, J., Suckow, M.A. \& Murthy, S. The IACUC Handbook 2nd edn. (CRC Press, Boca Raton, FL, 2007).

Strait is Assistant Professor and Clinical Veterinarian at Emory University, Atlanta, GA. 